\section{Fistulization of the right coronary artery to the superior vena cava}

Coronary artery fistulas are abnormal connections between the coronary arteries, and cardiac cavities and large vessels. The occurrence of reporting of a fistula between the right coronary artery (RCA) and vena cava superior (VCS) is very rare in the literature. This report presents the case of a 55 -year-old woman, wherein coronary Computed tomography (CT) angiography revealed a fistula between the VCS and the RCA.

A 53-year-old female patient was presented to the cardiology clinic with mild chest pain. Physical examination, vital findings, and laboratory results were normal. Her medical history did not reveal any known disease. Electrocardiography (ECG) showed no abnormalities in the leads V2-V6 except T flattening. However, echocardiography showed $65 \%$ ejection fraction. She had mild mitral insufficiency. The widths of the heart chambers were normal. The patient underwent coronary CT angiography because of the absence of electrolyte abnormalities that would cause T wave flattening. Coronary CT angiography revealed the formation of a fistula in the VCS from the nodal branch of the RCA (Fig. 1). Fistulized segment was dilated and tortuous. Other coronary artery branches were normal. The widths of the heart cavities were normal. Catheter coronary angiography revealed a clear fistula tract (Fig. 2). The ischemia region was not detected in myocardial perfusion scintigraphy. A close follow-up with medical treatment was recommended due to mild clinical findings and negative myocardial perfusion scintigraphy.

Informed consent: The author/s confirm that written consent for the submission and publication of this case report including image(s) and associated text was obtained from the patient.

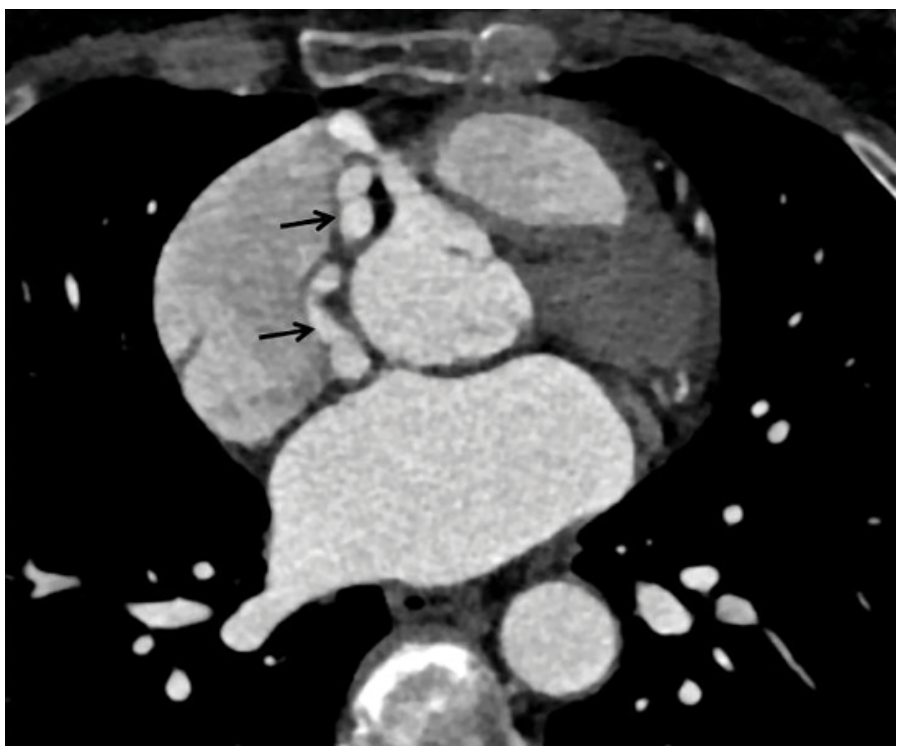

Figure 1. Coronary CT angiography shows a dilated and tortuous fistula segment (black arrow)

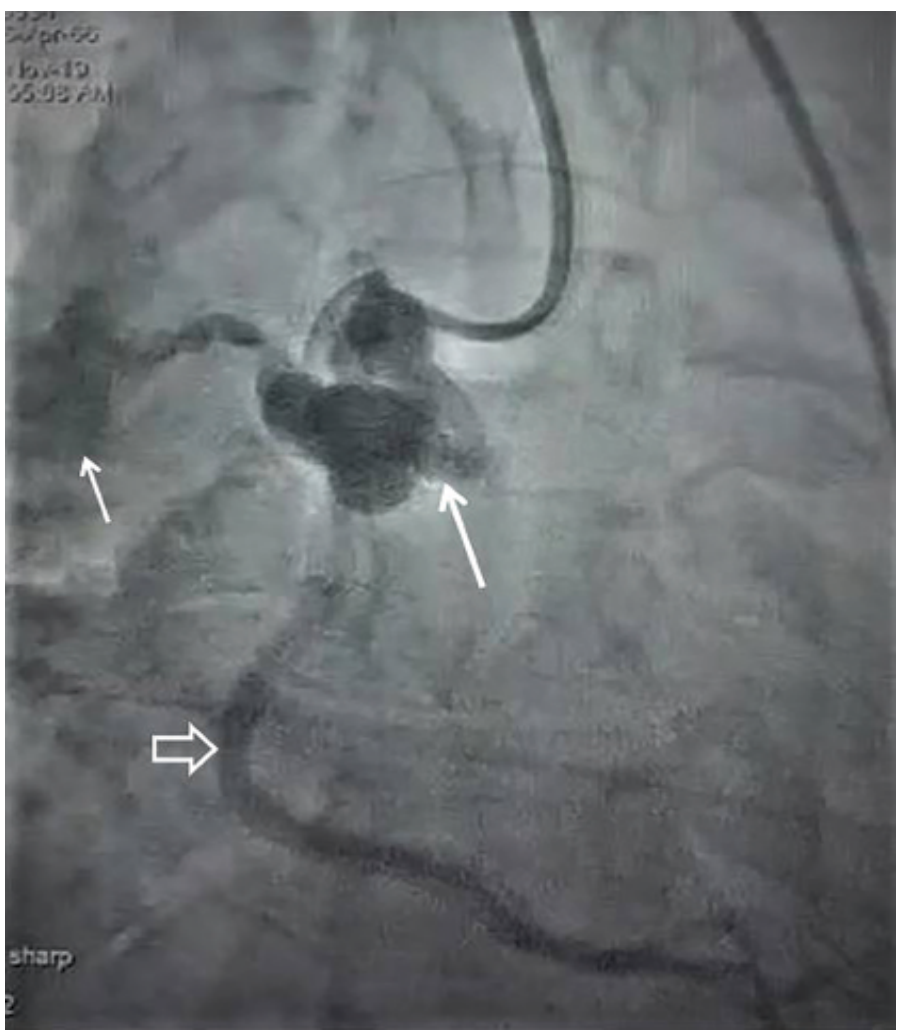

Figure 2. Catheter coronary angiography showed fistulization of the superior vena cava white arrow) from the nodal branch of the right coronary artery (open arrow)

\section{(D) Neşat Çullu*, (D) Murat Yunus Özdemir*, (D) Eda Özlek**, (D) Önder Yeniçeri*, (D) İbrahim Altun** \\ Departments of *Radiology, and **Cardiology, Faculty of Medicine, Muğla Sıtkı Koçman University; Muğla-Turkey}

Video 1. Axial coronary CT angiography showed fistulization of the superior vena cava from the nodal branch of the right coronary artery.

Video 2. Coronal coronary CT angiography showed fistulization of the superior vena cava from the nodal branch of the right coronary artery.

Video 3. Fistulized segment is observed in 3D CT angiography images (Volume Rendering Display).

Video 4. Fistulized segment is observed in 3D CT angiography Maximum Intensity Projection images.

Video 5. Catheter coronary angiography showed fistulization of the superior vena cava white arrow) from the nodal branch of the right coronary artery (cine images).

Address for Correspondence: Dr. Neşat Çullu,

Muğla Sıtkı Koçman Üniversitesi Tıp Fakültesi,

Radyoloji Anabilim Dalı,

Muğla-Türkiye

Phone: +90 5072030472

E-mail: nesatcullu77@gmail.com

CCopyright 2020 by Turkish Society of Cardiology - Available online

at www.anatoljcardiol.com

DOI:10.14744/AnatolJCardiol.2020.94727 